Review Article

\title{
The Use of Dialects in Education and Its Impacts on Students' Learning and Achievements
}

\author{
Wondimu Tegegne \\ College of Social Sciences and Humanities, Wolayita Soddo University, Wolayita Soddo, Ethiopia
}

Email address:

Wondelove7@gmail.com

To cite this article:

WondimuTegegne.The Use of Dialects in Education and Its Impacts on Students' Learning and Achievements. Education Journal. Vol. 4, No. 5, 2015, pp. 263-269. doi: 10.11648/j.edu.20150405.22

\begin{abstract}
It is argued that learning is better and more successful when conducted in the variety spoken by students. In addition, it is claimed that the use of students' variety in education enables students to use their own potential and helps them to achieve 'deep learning.' Besides, the use of students' native dialect in education enhances the social, cognitive, emotional and linguistic development of learners' in and out of school. For these reasons, it is argued that students need to be educated through their own variety. However, in multidialectal society, the issue of dialect and education in general and the issue of choosing the variety to be used as a Language of Instruction(LOI) in particular has been a great concern to linguists, educationalist and researchers for a long period of time (Yiakoumetti, 2007). This is because selecting the variety to be used as a LOI in multidialectal society is difficult as well as controversial. Besides, deciding the LOI largely depends on a variety of factors such as historical, economic, pedagogical, sociolinguistic, cultural, ideological, theoretical or/and political (UNESCO, 2003). For these reasons, the incorporation of dialects in educational system is questionable and contentious. This article is, therefore, intended to describe the use of dialects in education. Specifically, it will describes variations within the same language, social and regional dialects, standard and nonstandard varieties and their use in education the social evaluation of language varieties and its influence on their use in education, deficit and difference views and their influence on educational practice and the impacts of using dialects in education on students' learning and achievements.
\end{abstract}

Keywords: Language, Dialect, Standard Variety, Non Standard Varieties, Education, Learning, Achievement

\section{Introduction}

There are thousands of languages in the world. The difference across languages, which is referred to as multilingualism, is a common and natural phenomenon (Holmes, 2001: Romaine, 2000). Similarly, there are variations within a language. Hence, linguistic diversity is not only limited to multilingualism, but there are also variations within the same language. Wolfram et al., (1999) explained that every language differs from place to place and from group to group in various ways. It is generally argued that all languages exhibit a great deal of internal variations (Wardhaugh, 2006).

The notion of 'variety' in language is complex and controversial. In a broad sense, 'variety' refers to a number of different languages; in a narrow sense, it is used to refer to differences within a language. In this study, 'variety' is considered in its narrowest sense. In specific terms, a 'variety' of language refers to the different manifestations or realizations of a language (Hudson, 2001). The different varieties of the same language are discussed in the next part.

This review article is significant it that it will help us to understand the use of dialects in education. It could also inform teachers and other concerned bodies about the impacts of using dialects on the students' learning and achievements. Still the article is significant in that it can help us to take informed decision on the use and impacts of dialects in education.

\section{Variations Within the Same Language}

As indicated above, variations can be found within a 
language. There are infinite sources of variation in speech such as social status, gender, age, ethnicity, geographical location, profession and economic background of a speaker (Holmes, 2001). The social class or/and group in which language is used varies. In relation to this, Lehmann (1976: 275) wrote that "Young speakers have their own special speech patterns, and in many societies there are considerable differences among the speech patterns of various social classes." Accordingly, a single vowel may be pronounced in different ways and hence, no two people speak exactly the same (Fromkin et.al, 2003). But, some features of speech are shared by groups of speakers and become a means of differentiating one group from the other. In such a case, speech is a clear indicator of social group membership. Thus, from a speech of a person, it is possible to tell the gender, socio-economic, professional or educational background of a speaker (Trudgill, 2001).

Variations within a language can be formed because of various factors. It is realized in different ways and at different levels of a language. Sometimes variations in a language may occur because the speakers belong to a different geographical area (Syal and Jindal, 2005). If we take English, for instance, we observe that it is not a single variety; but it exists in several varieties. One variety of English is referred as to Received Pronunciation (RP) which is used in the south west of England, associated with the universities of Cambridge and Oxford, and BBC ( Sailzmann,2007:Wardhaugh, 2006). RP is the prestigious variety that is used in different formal situations such as in schools and media.

In addition, there are other varieties of English such as the English that is spoken in the north of England in Yorkshire and Lancashire, in Scotland (Scottish English), in Wales (Welsh English), etc. Sailzmann(2007:176) also said that "Because it is spoken in so many different areas the world over, English is particularly diversified dialectally" There are also different varieties of English spoken in various countries of the world such as in Africa, America, Australia, China and India (Trudgill, 2001). Varieties of a language that are formed in different geographical regions involve change in the pronunciation as well as vocabulary (Chambers and Trudgill, 2004). Such changes resulted in the formation different varieties of a language (See regional dialect in the next part).

The variations in a language are also formed due to a specific human activity in which language is used. It is common that in a society, various social groups are engaged in different kinds of activities. Individuals speak different varieties of a language according to their activity (Halliday and Hassan, 1990). Consequently, a single language can be used in different areas such as in law, science, sport, etc. (Syal and Jindal, 2005). In each of the areas, there is a specific vocabulary and way of using a language, such as what is observed in the language of medical doctors, legal officers, laboratory physicists, literary critics, etc (Gee 2002). In such areas, members of each group will choose their specific language variety to carry out their distinctive social activity. The variety of a language according to its use is known as register (Halliday and Hassan, 1990). Register reveals what we are doing (Romaine, 2000).

Besides, a specific social situation where a language is used can lead to the formation of language varieties. With this regard, Sailzmann (2007:177) noted that "The way individuals speak varies not only according to their regional and social dialects but also according to context. The distinctive manner in which people express themselves in a particular situation is referred to as style". On his part, Edwards (1995) described style as speech variation which reflects one's perception of the social context and what is or what is not 'appropriate.' Speakers of a language will use different forms of a language depending on the type of social situation in which they find themselves (Coupland and Jaworski, 1997). People vary their speech in accordance with the group in which they use the language (Hudson, 2001). For example, the speech of an individual on meeting and with a friend is different in that the former is characterized by formality and the latter one by informality. Similarly, we use different manner of speech with our children, wife, husband, bank manager, the vicar, in the pub and so on. Thus, the variety used in formal and informal situation is different depending on social context, relationships between participants, gender, age, physical environment and topic (Cook, 2003: Labov, 2003).

Moreover, there is another form of variation that is created because of the specific way of pronouncing words which is commonly called accent (Wolfram et al., 1999). People pronounce a single word differently. Thus, one's accent is the way he or she pronounces a word (Trudgill, 2001). Among these specific varieties of a language, the use of dialects in education is the focus of this review article.

The above varieties of language are closely related to each other and there are no restrictions on the relationship among the varieties (Hudson, 2001). They may overlap and one variety may include the other variety. As a result, it is problematic to provide a definition for each variety which clearly distinguishes it from the other. In addition, there is no consistent basis for grouping the variations. Rosenberg (1989) stated that linguistic variety is a complex issue whose meaning and use is governed by overlapping social, situational, political and psychological factors. For these reasons, there are great problems in delimiting one variety from the other variety of the same sort (e.g., one dialect from another dialect) and there are also great challenges in delimiting one kind of variety from the other (e.g., language and dialect) (Hudson, 2001).

\section{Types of Dialect: Social and Regional}

Dialect generally refers to the variety of a language characterized by its own distinct pronunciation, vocabulary and other grammatical features such as plural marker deletion, subject-verb agreement, use of negatives, etc. Different dialects can be formed when people are separated geographically and socially (Fromikin et al., 2003). Hence, the term dialect can be used to describe differences in speeches which are associated with geographical areas and 
social groups of a speaker (Wardhaugh, 2006). Besides, there are different ways of classifying dialects. One way to classify dialect is based on the social class and geographical background of a speaker. Based on these criteria, dialects are classified as: social dialects and regional dialects (Holmes, 2001).

However, like the controversies of the distinction between language and dialect, the difference between social and regional dialect is not clear. With this regard, Wolfram (1998: 75), said “... the notions of regional, social and ethnic dialect are not nearly as obvious as we might assume at first glance." This is because speakers a language could associate themselves at the same time with a number of different groups and their varying membership may contribute to the variety of a language they use. Wolfram further stated that speakers who are located within the same geographical area may associate themselves with quite different social groups and thus, speak quite disparate varieties, though they share a common regional language variety. Besides, Wardhaugh (2006) explained that defining social group or/and class is a problem since various factors such as occupation, place of residence, education, cultural background, religion, etc. are considered in defining it.

In spite of such complexities, scholars generally agree that one way of categorizing variations within a language is based on a social class or regional location of a speaker. Thus, variations in a language can be classified as regional variation and social variation, or technically as regional dialect and social dialect (Holmes, 2001). According to Wardhahugh (2006), regional dialect is the difference that one notices while traveling through a wide geographical area in which a language is used. It is also used to describe the geographical distributions of various linguistic features of a language (Holmes, 2001).

On the other hand, social dialect is the differences that are observed in a speech associated with social group and/or class of language speakers. It is used to differentiate one social group from the other group (Lehmann, 1976). Romaine (2000:2) described the two saying "Social dialects say who we are, and regional dialects say where we come from." In short, regional dialect is the separation which is made by physical condition and social dialect is the separation by social condition of a speaker.

\section{Standard and Non-Standard Dialects and Their Use in Education}

The language varieties spoken in certain community can be classified as standard and non-standard dialects. The standard dialect is a prestigious, codified variety that has the highest social status and used in formal occasions (Holmes, 2001: Sailzmann, 2007). The non-standard dialect is any variety of language which is not standardized and lacks prestige (Cook, 2003). Sometimes the standards variety is considered as a language, whereas the non-standard variety is considered as a dialect (Downes, 1998).
As noted earlier, the varieties of a language can be classified as regional dialect and social dialect based on speaker's geographical origin and social background. The educational implication of the regional and social dialects can be considered within the standard and non-standard category. This is because a variety spoken by a certain social group or region can be emerged as a standard variety; while the other varieties remain in the status of non-standard variety (Hudson, 2001).

It is argued that the varieties of a language play an important role in educational context. In this connection, learning is claimed to be better and more successful when conducted in the variety spoken by students (Cheshire, 2005). However, selecting and compromising standard and non-standard varieties in different spheres of life such as in education, politics, social, etc., seems complex and controversial. For example, Cook (2003:12) described the situation of practically using the two varieties in academic setting as follows:

At the heart of the aspiration to relate theory to practice is a constant tension between language as viewed by 'the expert' and language as everyone's lived experience. The two are by no means easily reconciled and... are likely to be aggravated by an attempt to impose insensitively an 'expert' view which runs contrary to deeply held belief. Nowhere is this more apparent than in our attitudes to the language education of children, and the belief which they reflect about the 'best'language use. These provide a good illustration of the kind of problematic issue with which applied linguistics enquiry engages.

Theoretically, the experts should value the different dialects of a language while preparing textbooks and National Exams. But as shown in the above extract, the variety used by experts is considered as a 'good' variety and positively valued. In multidialectal society, selecting the variety to be used as a LOI in multidialectal society is difficult as well as controversial. However, in most countries, the standard variety has been only used and taught in schools (Cheshire, 2005). The non-standard dialects have been officially unacceptable in schools (Rosenberg, 1989). On the other hand, students go to schools from both standard and non-standard varieties (Cheshire, 2007). Thus, there has been a mismatch between the varieties used at schools and those used at home. The use of dialects in education is affected by social evaluation of the varieties of a language, which is briefly discussed in the next section.

\section{The Social Evaluation of Language Varieties and Its Influence on Their Use in Education}

The varieties of language used by members of a society vary from group to group and place to place. Though all varieties are linguistically equivalent, speakers of a language often assign social value to the linguistic forms used by certain groups (Holmes, 2001). By attaching social value, the 
speakers categorize the language variants as socially prestigious or socially stigmatized. Wolfram (1998:84), described the two as "socially prestigious variants are those forms that are positively valued through their association with high status groups as linguistic markers of status; whereas, socially stigmatized variants carry a stigma through their association with low-status groups." This indicates that social value is given to the language variants considering the social status of a speaker. Most of the time the standard variety is taken as the prestigious variety; whereas, the non-standard variety is lacking prestigious and hence, taken as a stigmatized variety (Milroy, 2007).

In addition, considering the power (both economic and political) of the speakers, the varieties are given different values by language users. Accordingly, the standard variety is often considered as 'strong', 'correct', 'superior' and 'better' form of alanguage; whereas, the non-standard varieties are considered as 'weak', 'wrong', 'incorrect', 'dirty', and 'illogical' forms of a language (Cook,2003: Chambers,2008). However, linguists argue that all variants of a language are equal in terms of their linguistic system as well as the functions they serve. Various scholars (Hudson, 2001: Adger and Chirstian,2007: Reaser and Adger, 2008) indicated that the non-standard dialects are systematic and rule governed as the standard dialect, having their own sound features, lexical items and grammatical patterns. It is also argued that no dialect is better or worse than the other dialect (Romaine, 2000). Thus, the variants are preferred or stigmatized on non-linguistic grounds. The social evaluation of language varieties highly influenced their use in education.

Different arguments have been forwarded for the use of the language varieties in education. Those in favor of the standards variety argued that its use helps to keep the unity of a nation, enables students to have adequate educational resources and provides different social and professional benefits to the learners (Romaine, 2000: Yiakoumetti, 2007).

On the other hand, Papapavlou and Pavlos (2007) claimed that the use of the non-standard dialects in education facilitates the elevation of the status of the dialects in a society and prevents their possible extinction. The use of the nonstandard variety is also argued to provide educational advantages to learners as the variety is intimate to the student. In addition, students from a community go to school speaking the varieties spoken in their locality. In such cases, dialects, like languages, are considered as heritage of peoples and instruments for expression of cultures as well as markers of self image and group identity (Ugorjii, 2005).For this reason, it is argued that students need to be educated through their own variety. However, the social evaluation of and belief about language varieties has been affecting the selection of the language varieties for instructional purposes.

Despite the arguments for the use of the non-standard dialects in education, many schools continued to teach or use the standard variety, ignoring the non-standard dialect (Cheshire, 2005: Rosenberg, 1989). In schools, the standard dialect has been used for various purposes. For example, teaching materials have been prepared and teacher training has been given using the standard variety. During training, teachers are given no or little training about the varieties of a language and ways of treating linguistic diversity that they will encounter in the classroom while they become a teacher (Curran, 2003). After training, the teachers lack basic knowledge and understanding of thenon-standard dialects. Then, they tend to assume that dialects as deviations or errors in regular language usage (Romaine, 2000).

However, students go to school from both standard and non-standard varieties (Cheshire, 2007). There is no as such a homogenous classroom; every student brings unique cultural and linguistic backgrounds into classrooms (Mabyin, 2007). As a result, there has been a mismatch between the variety used at school and students' home dialects. This has lead to the arousal of controversial debates in a society and in a school regarding which variety should be used in education (Adger and Christian, 2007). The debate has been further continued with the development of two hypotheses about the varieties of a language.

\section{Deficit and Difference Views and Their Influence on Educational Practice}

Around the1960s and 1970s, two contradictory views regarding the nature and characteristics of language varieties were emerged. Deficit hypothesis is one view that considers the non-standard varieties as inadequate for communication. Wolfram et al.,(1999:20) explained that, "In terms of language, proponents of the deficit position believed that speakers of dialects with non-standard forms have a handicap-socially and cognitively-because the dialects are illogical, or sloppy, or just bad grammar.'Kangas(1999) stated that the speakers themselves and their characteristics is seen as a problem in deficiency theory. This view advocates the eradication of the use of dialects in schools favoring the standard dialect. This is because they are considered as inappropriate for instruction (Romaine, 2000). Thus, in a classroom dialects are prohibited and students are expected to use the standard variety. For this reason, students from the non- standard background are forced to attend their education through the standard dialect.

The differences hypothesis, on the other hand, argued that all languages and dialects are regular and have rule-governed system. The advocators of this view claimed that there are no linguistic grounds for arguing that one variety is superior to another (Cheshire et al., 1989). Wolfram et al,(1999:20)expressed the position of difference hypothesis saying, "Because no one linguistic system can be shown to be inherently better, there is no reason to assume that using a particular dialect can be associated with having any kind of inherent deficit or advantage."In addition, Romaine (2000) said that different groups have different ways of using their own language. Thus, the non-standard dialects are not deficient; rather they are different way of expressing ideas. This hypothesis advocates that the non-standard varieties can be used for educational purposes.

These views have been reflected, implicitly or explicitly, in 
educational polices and particularly in teachers' classroom practice. For example, teachers negatively respond to the dialects used by African American students and correct dialects forms when used by students (Washington, 2001). In America, it was also found out that teachers encourage the style and dialects used by white students and discourage the varieties of the black students (Romaine, 2000). However, in some counties, like in Switzerland and Italy, dialects are used for classroom instruction. This shows that the two points of view have been influencing the practice of educational programs and affecting the learning, positively or negatively, of the dialect speakers.

\section{The Impacts of Using Dialects in Education on Students' Learning and Achievements}

The rights of the different dialect speakers and equal opportunities in education for them have long been social and academic issue in various parts of the world (Cheshire et al., 1989). The impact of dialectal variations on the learning and achievement of learners has been also the focus of many researchers. However, the studies conducted on the use of dialects in education reported two contradictory findings.

In some countries, for example, it was found out that there is no clear evidence that show that dialect speakers are disadvantaged in schools. Regarding this, Jorgensen and Pedersen (1989) reported that dialect speaking students in Denmark are not at clear disadvantage with respect to education as compared with standard speakers. This could be resulted from the attitude and tolerance towards dialects and their usage in schools. In some countries, such as Germany, teachers are tolerant to the use of dialect forms. In such areas, the use of dialect is not ridiculed and thus, students may not face challenges in their learning.In addition, the ability of dialect speakers to use or switch to the standard variety could also contribute to the positive result.

In other countries, however, it has been pointed out that dialect speakers were negatively affected in education. Hagen (1989), for instance, reported that in Netherlands dialect speakers experience problems in their education with respect to learning and achievements of language skills and other school subjects. Adger et al., (1993), also noted that African American dialect speakers are at disadvantage in their education. It is generally said that dialect speakers face various challenges in their learning (Chambers, 2008).For example, dialect speakers face challenges in learning to read in the classroom (Hudson, 2001). This is because the students are less likely to find predictable features of their dialect in textbooks. Reaser and Adger (2008) stated that African American dialect speakers have more difficulty to read because of dialect differences. In such cases, standard speakers are more likely to have an advantage over dialect speakers (Romaine, 2000). Many materials used in classrooms are prepared in a standard dialect and students speaking the standard are familiar with the sounds and vocabulary of the standard dialect. So it is easier for the standard dialect speakers to read and understand than for the students speaking the non-standard dialect.

The negative impression and the treatment of the non-standard varieties in schools can also affect students' learning. A student whose home variety is a non-standard is often ridiculed in schools by their teachers and friends. For instance, in Britain, speakers of Breton, Welsh and Gaelic were subjected to ridicule and corporal punishment for using their native variety (Cheshire and Trudgill, 1989). This made the students remain silent in the classroom. Students who remain silent cannot receive equal instruction and find it difficult to achieve their goals.Regarding this, Kangas(1999), however, stated that a good educational program provides a fair chance of academic achievement at school. That means schools should be a place of equal chance for all students regardless of their linguistic background.

The other impact of standard dialect use in school comes in assessment form (Adger and Christian, 2007). Differences in dialect should not be counted against students regarding their ability to learn or understanding of concepts (Wolfram et al., 1999).However, Exams are mainly prepared using the standard dialect. Hence, the dialect used on tests creates a bias against students who do not speak a standard dialect. With this regard, Wolfram (1991) said that instead of testing content, most tests measure how proficient students are in the standard dialect. Besides, Wolfram et al., (1999) stated that objective tests of language usage may be difficult for students from the non-standard dialect background because such tests tend to focus on points of dialect differences in usage. For this reason, administering standard dialect usage as measures of language ability can affect the test scores of the dialects speakers and make them disadvantaged.

In addition, test items are mostly constructed in standard dialect requiring students to provide a correct answer. The correctness is judged in terms of the standard dialect usage and thus, the uses of non-standard forms in responding to the questions are considered as incorrect (Wolfram, 1991). Romaine (2000: 208) stated that "Because schools measure success in terms of mastery of the Standard English (or whatever the accepted language in society is) non-standard speech is seen as illogical..."Besides, teachers believed that the interference of dialect should be corrected in written work and in formal oral activities (Gimbel, cited in Jorgensen and Pedersen, 1989). These indicate that students who speak dialects are misunderstood by their teachers and affected by inappropriate assessment of their teachers.

Furthermore, tests prepared in the standard dialect are not only language challenging for non-standard speakers, but are also difficult to understand contextually. There are many culture biases within the tests. Many reading passages and content questions evaluate students with questions related to standard culture. With this regard, Romaine (2000:206) stated that "Children who do not come to school with the kind of cultural and linguistic background supported in the schools, are likely to experience conflict.'In addition, Mohammed (2002) noted that students and teachers can face barriers in the 
learning and teaching process due to dialect and cultural differences.

Dialects used to prepare Exams can also affect the performance of students on Exam (Adger and Christian, 2007). For example, in a study conducted by Solano-Flores and $\operatorname{Li}(2006: 16)$, it was found out that “....students preformed better on items administered in their local dialect than in their standard dialect of Haitian-Creole." Similarly, Reaser and Adger (2008) noted that reading achievements is clearly correlated with production of standard dialect: students who speak the standard dialect score more than those who do not. In addition to performance on language skills, dialect used on tests also affect students' performance on other subjects (Wolfram, 1991). Concerning this, Washington (2001), said that school aged African American students consistently perform below their white peers in reading, mathematics and science and cultural differences, dialect differences and assessment practices were identified as key factors affecting their performance.

\section{Summary}

Deciding the dialects that should be used for instruction is a question of great interest that raised hot debate in different parts of the world. However, in most countries, the standard variety has been only used and taught in schools for long period of time (Cheshire, 2005). For years the non-standard dialects have been not used in schools. After the standard dialect began to be used in education, it has been shown that non-standard dialect speakers face challenges in their education. Rosenberg (1989:62) stated that "The existence of specific educational difficulties experienced by dialect speaking children is, thus, by no means a recent discovery."

Currently, educational issues concerning dialectal variations have received popular attention worldwide (Papapavou and Pavlos, 2007). It is argued that the varieties of a language play an important role in an academic setting. Learning is claimed to be better and more successful when conducted in the variety spoken by students (Cheshire, 2005). Cheshire (2007: 22) further noted, "There is general consensus, in fact, among educationalist and sociolinguistics alike, that valuing dialect in the classroom makes real difference to educational achievement of speakers." Derebsa (2006) also argued that the use of the students' variety in education enables the students to use their own potential and helps them to achieve 'deep learning.' Besides, the consideration of dialects in education enhances the social, cognitive, emotional and linguistic development of learners' in and out of school. To solve the challenges that the learners face due to the use of standard variety and to help students get the benefits of learning in their own variety, it is argued that the varieties of a language deserve respect and recognition in schools.

\section{References}

[1] Adger, C. and Christian, D. (2007). Sociolinguistic variation and education. In Bayley, R. andLucas, C. (Eds). (2007). Sociolinguistic variation: Theories, methods, and applications (237-253) Retrieved from: WWW.Cambridge.Org/9780521871273

[2] Adger, C., Wolfram, M. and Detwyler, J. (1993). Confronting dialect minority issues in special education: Reactive and proactive perspectives. Third National Research Symposium on Limited English Proficient Student: Focus on middle and high school issues.

[3] Chambers, J. K. (2008). Studying language variation: An informal epistemology. In Chambers, J.K, Trudgill, P. and Schilling-Estes, N. (Eds). (2008). Handbook of language variation and change (7-15). Retrieved fromhttp://www.blackwellreference.com/ subscriber/book?

[4] Chambers, J.K. and Trudgill, P. (2004). Dialectology $\left(2^{\text {nd }}\right.$ ed). Cambridge: Cambridge University Press.

[5] Cheshire, J. and Trudgill, P. (1989). Dialect and education in the United Kingdom. In Cheshire, J., Edwards, V., Munstermann, H. and Weltens., B. (Eds). (1989). Dialect and education: Some European perspectives (94-112). Philadelphia: Multilingual Matters Ltd.

[6] Cheshire, J. (2005). Sociolinguistics and mother tongue education. In Ammon, U., Dittmar, N. and Trudgill, P.(Eds). (2005). Sociolinguistics: An introductory handbook of the science of language and society $\left(2^{\text {nd }}\right)(2341-2350)$. Berlin: Moutonde Gruyter.

[7] Cheshire, J.(2007). Dialect and education: Responses from sociolinguistics. In Papapavou, A. and Pavlos, P. (Eds). (2007). Sociolinguistics and pedagogical dimensions of dialect in education (14-33). Newcastle: Cambridge Scholars Publishing.

[8] Cook, G. (2003). Applied Linguistics. Oxford: Oxford University Press.

[9] Coupland, N. and Jaworski, A.(Eds).(1997). Sociolinguistics: A reader and course book. New York: Pal grave Macmillan.

[10] Curran, M.E. (2003). Linguistic diversity and classroom management. Theory into Practice, 42(4), 334-340.

[11] Edwards, J. (1995). Multilingualism. London: Penguin Books.

[12] Fromkin, V., Rodman, R. and Hyams, N 2003). An introduction to language (7ed).Boston: Michael Rosenberg

[13] Gee, P. (2002). Educational Linguistics. In Aronoff, M. And Rees-Miller, J,. (Eds). (2002). The handbook of linguistics (485-496). Blackwell Reference Online. Retrieved from: http://www.blackwellreference.com/subscriber/book?id=g978 1405102520_9781405102520

[14] Hagen, A. (1989).Dialect, Frisian and education in the Netherlands. In Cheshire et al., (Eds). (1989). Dialect and education: Some European perspectives (48-61).Philadelphia: Multilingual Matters Ltd.

[15] Halliday, M.A. K. and Hassan, R. (1990). Language context and text: Aspects of language in a social-semiotic perspective. Oxford: Oxford University Press. 
[16] Holmes, J. (2001). An introduction to Sociolinguistics. Malaysia: Pearson Education Limited.

[17] Hudson, R.A. (2001). Sociolinguistics (2 ${ }^{\text {nd }}$ ed).Cambridge: Cambridge University Press.

[18] Jorgensen, J.N. and Pedersen, K. M.(1989). Dialect and education in Denmark. In Cheshireetal., (Eds). (1989).Dialect and education: Some European perspectives (30-47). Philadelphia. Multilingual Matters Ltd.

[19] Kagas, T. (1999). Education of minorities. In Fishman, J.(Eds). (1999).Hand book of language and ethnic identity (42 -59). Oxford. Oxford University Press.

[20] Labov, W. (2003). Some sociolinguistic principles. In Pauloston, B and Tucker, R. (Eds).(2003).The Sociolinguistic: The essential readings(234-301). Blackwell Publishing Ltd.

[21] Lehmann, W.P. (1976). Descriptive Linguistics: An introduction. New York: Random House.

[22] Maybin, J. (2007). Language and education. In Liamas, C., Mullany, L., and Stockwell, P.(Eds). (2007). The Rutledge companion to Sociolinguistics (157-163). New York: Taylor and Francis Group.

[23] Milroy, J.(2007). The Ideology of standard language. In Liamas et al., (Eds). (2007).The Rutledge companion to Sociolinguistics (133-139). New York: Taylor and Francis Group.

[24] Mohammed, T.(2002). An exploration of students' and teachers' attitude towards Ebonics in a Community College Writng Program, Retrieved from: ERIC database (Ed 479490).

[25] Papapavou, A and Pavlos, P.(Eds).(2007).Sociolinguistics and pedagogical dimensions of dialect in education. Newcastle: Cambridge Scholars Publishing.

[26] Reaser, J. and Adger, C. (2008). Vernacular language varieties in educational settings: Research and development. In Spolisky, B. and Hult, M.(Eds). (2008).The handbook of educational Linguistics (161-173). Malden: Blackwell Publishing Ltd.

[27] Romaine, S.(2000). Language in society: An introduction to Sociolinguistics $\left(2^{\text {nd }} e d\right)$. Oxford: OUP.
[28] Rosenberg, P. (1989). Dialect and education in West Germany. InCheshire et al., (Eds). (1989).Dialect and education: Some European perspectives (62-93).Philadelphia: Multilingual Matters Ltd.

[29] Sailzmann, Z. (2007). Language, Culture and society (Fourth edition). USA: West view Press.

[30] Solano-Flores, G. and Li, M. (2006). The use of generalizability (G) theory in the testing of linguistic minorities. Educational Measurement: Issues and Practice, 25(1), 13-22.

[31] Syal, P and Jindal, D. V. (2005). An introduction to Linguistics: Language, grammar and semantics. New Delhi: Prentice Hall of India.

[32] Trudgill, P. (2001). Dialects: Language workbooks. London: Taylor and Francis Group.

[33] Ugorjii, U.C. (2005). Dialect communities and language vitality: The case of Igbo. Journal of West African Languages, $32,(1), 33-43$.

[34] UNESCO (2003). Education in a Multilingual World and Mother Tongue Education. France: UNESCO

[35] Wardhaugh, R.(2006). An Introduction to Sociolinguistics $\left(6^{\text {th }}\right.$ ed). Cambridge: Blackwell Black well Publishing Ltd.

[36] Washington, J. A. (2001). Early literacy skills in African American children: Research considerations. Learning Disabilities Research and Practice, 16(4), 213-221.

[37] Wolfram, et al. (1999). Dialects in schools and communities. Mahwah: Lawrence Erlbaum Associate Publishers.

[38] Wolfram, W. (1991). Dialect differences and testing. Retrieved from: ERIC database (Ed323813).

[39] Wolfram, W. (1998). Dialect in society. In Coulmas, F.(Ed). (1998).Hand book of sociolinguistics (75-87). Retrieved from http://www.blackwellreference.com/subscriber/tocnode?

[40] Yiakoumetti, A. (2007). Choice of classroom language in bi-dialectal communities: To include or to exclude the dialect? Cambridge Journal of Education, 37(1), 51-66. 